\title{
A Neurociência na formação do professor de Física: Análise curricular das licenciaturas em Física da região Sul do Brasil
}

\section{Neuroscience in shaping the physics teacher: Curriculum analysis of undergraduate in physics in Southern Brazil}

\author{
Patrick Alves Vizzotto (patrick.fisica@ hotmail.com)
}

\author{
Universidade Federal do Rio Grande do Sul (UFRGS)
}

\begin{abstract}
Resumo: É investigado se os cursos de formação de professores de Física possuem em seus currículos disciplinas que ensinem conceitos de neurociência aos futuros docentes. Através de uma pesquisa documental, analisou-se o conteúdo de 33 matrizes curriculares de licenciaturas de Física do Sul do Brasil. Como resultado, observou-se que a relação entre as duas áreas ainda não é realidade efetiva dentro da formação do professor de Física. Sugere-se para estudos futuros a ampliação da investigação à nível nacional, a fim de fornecer um panorama geral da realidade estudada, a fim de que discussões como estas possam sensibilizar pesquisadores e formadores de professores para a importância do trabalho interdisciplinar entre as áreas supracitadas, com o objetivo de formar um professor que compreenda de forma abrangente seus alunos, desde o que os move para aprender, até mesmo quais estratégias de ensino necessitam ser aplicadas e outras, revisadas, para uma aprendizagem de maior significado.
\end{abstract}

Palavras-chave: Neurociência. Ensino de Física. Formação de professores.

\begin{abstract}
Is investigated if the training courses of Physics teachers have in their curricula courses that teach concepts of neuroscience to future teachers. Through a documentary research, analyzed the content of curriculum matrices of 33 degrees in physics from southern Brazil. As a result, it was observed that the relationship between the two areas is not yet effective reality within the formation of the physics teacher. It is suggested for future studies to expand the investigation to the national level, in order to provide an overview of the reality studied in order that discussions like these can sensitize researchers and teacher trainers for the importance of the work between the above-mentioned areas interdisciplinary, with the goal of forming a teacher who understands his students in a comprehensive manner, since the move to learn, even what teaching strategies need to be applied and other, revised, for a learning more meaningful.
\end{abstract}

Keywords: Physics teaching. Training of teachers. 


\section{INTRODUÇÃO}

A neurociência estuda o sistema nervoso central bem como sua complexidade (BARTOSZECK, 2006). Acredita-se que os conhecimentos advindos de tal área possam contribuir com a educação, para que os professores adquiram mais uma referência na compreensão de como as práticas educativas podem influenciar nas configurações cerebrais de cada aluno, através do estudo da biologia, anatomia e fisiologia do cérebro.

Dessa maneira, a neurociência dialoga com a educação, pois fundamenta a compreensão do processo de aprendizagem do ponto de vista fisiológico, estrutural, funcional e patológico do ser humano, investigando assuntos referentes à memória, humor, atenção, sono; ou seja, o comportamento geral que pode influenciar o processo de aprender.

A neurociência como uma ciência formal teve seu início no século XIX, com estudos de estímulos cerebrais, nos quais percebeu-se que todo cérebro responde a mudanças e estas acontecem através de sinapses neurais. Eric Kandel, considerado o pai da neurociência, disse que somos produto das nossas sinapses: "somos quem somos por causa daquilo que aprendemos e do que lembramos" (FERNANDES, 2006, p. 40). Isto é, todos os cérebros são possíveis de se alterar e de mudar, o que levou a concluir que o cérebro tem a capacidade de mudar através de novas aprendizagens (RELVAS, 2011).

Sob a perspectiva neurocientífica, pode-se dizer que o processo de aprender está relacionado às bases químicas e físicas na função neural. Por conseguinte, essa composição Química e Física funciona em uma estrutura, de maneira que ela possa receber, transmitir e decodificar informações, ou seja, a neurociência tem uma contribuição importante, pois amplia a compreensão do funcionamento do cérebro.

Para isso, estuda-se grupos de neurônios que estejam alicerçados dentro de um circuito de conexões, como por exemplo: a relação do cérebro com as funções musculares. Existem fibras nervosas que estão inseridas nos músculos e com isso formam um sistema neuromuscular que proporciona a condição de escrita, fala e leitura (ANDRADE; PRADO, 2003). Não obstante, tudo isso está condicionado ao comportamento, sendo esta, outra releitura que a neurociência, ao mesmo tempo proporciona, ao buscar entender o comportamento dos alunos na sala de aula. 
Outra importante função dessa interface entre neurociência e educação é entender como se processam os pensamentos, a memória, o planejamento, as habilidades e as formas motoras que são condicionadas na sala de aula e na escola de modo geral.

De acordo com Relvas (2009) as pesquisas científicas em neurociência começaram no início do século XIX. Nessa ocasião, os fisiologistas Gustav Fritsch e Eduard Hitzig relataram que as estimulações elétricas de áreas específicas do córtex cerebral provocavam movimentos. Broca e Wernicke, destacaram-se por confirmar que a linguagem também é organizada em áreas específicas no córtex cerebral. Em 1890, o cientista Jamon Cajal estabeleceu que cada célula nervosa é única, distinta e individual e que essas células respondem a estímulos, sendo conectadas por sinapses. Em 1970 desenvolveu-se novas técnicas produzidas por imagens, a fim de fornecer informações fisiológicas e patológicas nunca antes desenvolvidas, através da tomografia computadorizada e ressonância magnética.

A neurociência traz para a educação a discussão de como o conhecimento da memória, do esquecimento, sono, atenção, medo, humor, afetividade, movimento, sentidos e linguagem são estruturadas fisiologicamente nos cérebros dos seres humanos. Tudo isso pode se tornar conhecimento fundamental para compreensão e planejamento da ação pedagógica, se estudado com cautela, pois segundo Guerra (2011) “a educação pode se beneficiar dos conhecimentos da neurobiologia para abordagem das dificuldades escolares e suas intervenções terapêuticas. A reflexão sobre as possibilidades e desafios do diálogo entre a neurociência e a educação pode trazer avanços para ambas as áreas" (p. 8).

Sendo assim, considerando a relevância da relação entre estas duas áreas e acreditando que tais interlocuções seriam importantes de acontecer desde a formação inicial do professor, o objetivo deste artigo é analisar as matrizes curriculares dos cursos de licenciatura em Física da região Sul do país, a fim de verificar se há disciplinas de neurociência ou outras relacionadas com o tema na formação inicial do professor de Física.

Esta pesquisa mostra-se relevante para a área do Ensino de Física pois fornece subsídios aos pesquisadores, formadores de professores e professores em formação, para que se discuta a realidade das grades curriculares das licenciaturas da área. Esta 
concepção defende que é relevante conhecer aspectos neurocientíficos para o aprimoramento da formação e futura atuação pedagógica do docente, pois pode possibilitar a formação de um profissional que aborde a Física com estratégias de maior efetividade de resultado na aprendizagem do aluno.

Em outras áreas do ensino, estudos semelhantes analisaram esta relação com a neurociência, sendo estes nas áreas da pedagogia (GROSSI, et. al., 2014), e da matemática (FONSECA; CÁSSIA, 2012), nos quais, compartilham do entendimento de que estas discussões são importantes, e o desejo de que dessas produções possa surgir um movimento de conscientização da relevância de tal abordagem interdisciplinar entre tais áreas do conhecimento.

\section{RELAÇÕES ENTRE A NEUROCIÊNCIA, APRENDIZAGEM E EDUCAÇÃO}

O que se entende por aprendizagem? Esse questionamento, inicialmente objeto de estudo de pesquisadores da área da psicologia, ramificou a área em psicologia do desenvolvimento ou psicologia da aprendizagem, e tem como problemática entender o funcionamento das funções cognitivas.

Porém, há décadas são realizados estudos buscando entender esse contexto e ainda não existe um consenso entre os autores clássicos e pesquisadores contemporâneos sobre como a mente humana aprende e o quais são os mecanismos que o cérebro utiliza para esse acontecimento.

As teorias da aprendizagem, no entanto, utilizam em seus estudos metodologias indiretas de medida a fim de verificar a retenção de conceitos ou ações condicionadas, com vistas a compreender as peculiaridades desse processo de aprender.

Inicialmente, acreditava-se que aprender dependia de fatores externos ao indivíduo e que o contato com o mundo, por meio dos sentidos, proporcionaria a integração necessária para "adquirir" conhecimentos. Essa concepção foi defendida pela linha que se denomina hoje de natureza empirista/indutivista, que agrega a teoria Behaviorista.

Porém, essa compreensão era altamente questionável pois a confiança nos sentidos humanos poderia facilmente ludibriar a validade das medidas realizadas, pois 
são instrumentos passíveis de falhas. No outro extremo, acreditava-se que a aprendizagem ocorria devido à interação com o meio, através de raciocínios dedutivos. Essa linha, chamada de racionalista, teve como principais representantes Piaget e Vygotsky, com as visões cognitivistas e sociointeracionistas, respectivamente.

Há ainda autores que concebem que nem o extremo empirista nem o racionalista representam os processos que englobam, de maneira completa, todos os aspectos fundamentais para compreender a aprendizagem. Ou seja, é necessária uma integração entre as duas concepções a fim de contemplar as possíveis influências que corroboram para esse fenômeno. Entre esses autores, destaca-se David Ausubel, que terá a sua Teoria da Aprendizagem Significativa abordada com maior ênfase na seção seguinte.

Não obstante, é relevante refletir sobre o papel da neurociência para a compreensão da aprendizagem. Pela primeira vez, esse campo de estudo tem a oportunidade de observar, por meio de observações diretas, o funcionamento cerebral, as sinapses e como as várias regiões do cérebro podem atuar durante o processo de interação com os conhecimentos.

Por ser um campo ainda em ascensão no contexto educacional, suas implicações não serão objetos de análise dos resultados da pesquisa, porém, são dignas de menção como uma área do conhecimento que fará contribuições com potencial de impactar na maneira com que se compreende os processos de ensino e aprendizagem.

É importante compreender como os cérebros aprendem e guardam informações. Tudo isso explica-se através da neurociência celular. O neurônio é uma célula estrelada, longa e está em todas as estruturas corpo, em um número médio de 100 bilhões (LENT, 2004). Os neurônios realizam uma importante função que é a de receber, responder, decodificar e armazenar estímulos, transformando-os em informação. Existe uma funcionalidade do neurônio chamada de sinapse, que é a passagem da informação de um neurônio para outro.

Os neurônios são constituídos na sua estrutura anatômica por um corpo celular, um prolongamento denominado axônio e filamentos denominados dendritos. $\mathrm{O}$ axônio leva o impulso nervoso para seus filamentos e dessa maneira a informação, que é transmitida pelos dendritos, passa no corpo celular, decodifica, armazena e é impulsionada através também do axônio para outras células do sistema nervoso central. 
A informação transmitida não se dispersa durante este processo devido a um isolante chamado de bainha de mielina, uma proteína que envolve o neurônio. As informações externas chegam ao cérebro através dos sentidos biológicos, que são canais constituídos de nervos, que levam ao cérebro todas essas informações. Nervos são constituídos de neurônios, que por sua vez, são constituídos de estrutura de corpo celular, axônios e detritos.

Dessa maneira, os neurônios respondem a uma capacidade funcional importante: o estímulo. Todo neurônio necessita ser estimulado. Segundo Relvas (2011), este processo pode ser explicado através de quatro propriedades: a primeira é a da irritabilidade, quando a célula detecta as modificações do meio ambiente. A segunda é quando ele conduz uma propriedade de condutibilidade, que significa passar a informação de um neurônio para outro. O neurônio também realiza uma contratilidade, ou seja, ele tem um movimento próprio e também está relacionado à propriedade da excitabilidade, pois todo o neurônio perpassa pela ação de receber e transformar a informação em respostas.

Dentro da educação, isso implica no fato de que se o aluno não está aprendendo determinado conteúdo é porque ele não encontrou referências em sua estrutura neural para abrigar essas novas informações. Por isso, de acordo com Brockington (2011), é importante reestruturar a informação, verificar de que maneira ela será mais interessante para que possa acontecer a aprendizagem.

Os estímulos acontecem através das sinapses. Fisiologicamente, existem dois tipos de sinapses: a Física e a química (LENT, 2004). A sinapse Física é aquela que vem do ambiente para o corpo interno, significa que há um canal de comunicação através dos sentidos. São os canais abertos para o cérebro, no qual existe uma estrutura chamada de tálamo, que recebe a informação e a distribui para todas as áreas do cérebro. A outra é a sinapse química, que está ligada ao sistema neuroendócrino, pois há uma relação entre glândulas e o sistema nervoso central. O hipotálamo e a hipófise atuam nesse processo.

A diferença entre as duas sinapses é que a sinapse química é lenta, duradoura e o que ela secreta e distribui através da corrente sanguínea são os neurotransmissores. Ou seja, aprende-se de duas maneiras: através da sinapse Física, que vem do meio externo 
para o meio interno e através de um sistema natural de emissários químicos denominados de neurotransmissores.

Com base nessas definições, nota-se que um ensino significativo provoca alterações na taxa de conexão sináptica e afeta a função cerebral, o que para a psicologia cognitiva, com vistas a estabelecer um paralelo, dentro da teoria de Ausubel pode ser denominado de Aprendizagem Significativa (AUSUBEL, 2003).

Para tal alteração acontecer de forma efetiva é importante destacar a relevância do currículo, dos métodos de ensino, a disposição emocional do estudante, o incentivo familiar, nutricional, etc. Todos esses fatores interferem na possibilidade de aprendizagem de cada indivíduo (BROCKINGTON, 2011).

O cérebro possui plasticidade, e por isso, para Oliveira (2014), necessita ser desafiado, estimulado e reestruturado a todo o tempo. A cada experiência existe uma nova conexão, dando surgimento à novas sinapses neurais. Pode-se dizer que um ser humano nunca é o mesmo à medida que se articula com novas informações, pois o cérebro é moldável a novas situações. Tal concepção incentiva a escola a buscar desafiar os alunos, estimulando-os a estabelecerem ligações significativas aos conceitos ensinados.

De acordo com a tradição, sempre foi privilegiado o viés cognitivo dentro da escola, no qual se prevalece majoritariamente o pensamento racional (GUERRA, 2011). De modo complementar, a neurociência destaca a importância do conhecimento da emoção dos alunos.

Uma das preocupações na sala de aula é o que o aluno precisa memorizar. A memória está localizada na região temporal, chamada de hipocampo, localizada acima das orelhas. A memória se torna significativa à medida que esse sujeito apreende, entende e compreende aquilo que faz sentido (IZQUIERDO, 2010).

O contrário disso, deixa de ser memória e passa a ser algo decorado. Para Izquierdo (2006) o decorar é, de certa forma, também importante na escola, só que esse decorar passa pelo primeiro estágio da memória, chamado de memória de trabalho.

Por exemplo, memorizar um número de telefone celular: A partir do momento que faz sentido possuir uma sequência de números decorados, essa memória de trabalho é levada para o hipocampo e assim memoriza-se aquilo que para o indivíduo é importante, 
no caso, o número de celular. Então o decorar é de certa forma fundamental, porém o memorizar é aquilo que traz sentido e significado para o indivíduo.

Portanto, a memorização é complexa e envolve sofisticadas reações químicas e circuitos interligados de neurônios. Conforme referido, as células nervosas quando ativadas por hormônios ou neurotransmissores atingem outras células nervosas através de ligações denominadas sinapses. As alterações decorrentes da aprendizagem constituem a memória, e sua capacidade de se moldar é chamada de plasticidade neural (LENT, 2004).

Quanto maior o número de conexões, melhor a memória, sendo assim, fundamental estimular tais reações, pois estas proporcionarão a formação de redes neurais estáveis com as novas informações assimiladas. O contrário poderá incentivar menores taxas de retenção. Nesse sentido, se defende a importância de um saber socializado se conectar com conhecimentos prévios relevantes, já presente na estrutura cognitiva/neural do aprendiz.

A neurociência possui ferramentas que possibilitam conectar as medidas indiretas realizadas por autores clássicos da psicologia da aprendizagem com o funcionamento real de um cérebro. São numerosas as frentes potenciais para temáticas de estudo dentro do ensino e aprendizagem e poderão contribuir de maneira substancial dentro de pesquisas semelhantes a essa, que se dedicam inferir aspectos da retenção e manuseio de saberes.

Conhecer tais aspectos pode consistir em um caminho no qual, juntamente com as teorias da aprendizagem advindas da psicologia, podem ser utilizadas para se refletir quais estratégias de ensino possibilitam gerar aprendizagens de maior êxito. Portanto, questiona-se se cursos de licenciatura oferecem de modo disciplinar, oportunidades para que tais assuntos possam ser debatidos.

\section{METODOLOGIA}

Este trabalho buscou investigar se os currículos dos cursos de licenciaturas em Física dos três estados da região Sul do país ofertam disciplinas de neurociência ou disciplinas relacionadas com a temática aos seus professores em formação. 
Essa pesquisa caracteriza-se quanto à sua natureza, como uma pesquisa de base, com o objetivo exploratório, o que na visão de Gil (2007) busca proporcionar maior familiaridade com o fenômeno estudado. Para este fim, utilizou-se como procedimento, a análise documental das referidas matrizes curriculares dos cursos de licenciatura em Física do Sul do Brasil.

Os cursos analisados necessitavam atender os pré-requisitos de estarem credenciados junto ao Ministério da Educação - MEC, e possuírem os currículos disponibilizados em sitio eletrônico.

A pesquisa aconteceu no segundo semestre de 2018 , na qual teve como ponto de partida o mapeamento dos cursos de licenciatura em Física existentes na região delimitada. No total, 40 cursos estavam cadastrados junto ao MEC. Em seguida, foi acessada a página eletrônica de cada um dos cursos com o objetivo de localizar a grade curricular vigente. Terminado este procedimento, passou-se ao momento de apreciação dos dados coletados.

Esse processo consistiu em analisar cada uma das matrizes curriculares e observar se nas mesmas haviam cursos relacionados com a neurociência dentro das disciplinas obrigatórias do currículo.

Os resultados desta análise encontram-se na seção a seguir.

\section{RESULTADOS}

Um total de 40 cursos de licenciatura em Física foram pesquisados, relação advinda de um relatório emitido pelo sitio do MEC. Desse total, 15 no estado do Paraná, 9 em Santa Catarina e 16 no Rio Grande do Sul.

Os resultados da busca demonstram a inexistência de disciplinas regulares que abordem conceitos de neurociência na formação do professor de Física. O quadro a seguir detalha os resultados quantitativos desta investigação.

Quadro 1 - Resultado quantitativo da pesquisa documental. Fonte: autor.

\begin{tabular}{|l|c|c|c|}
\hline Estado & $\begin{array}{c}\text { Total de } \\
\text { instituições } \\
\text { pesquisadas }\end{array}$ & $\begin{array}{c}\text { Instituições sem } \\
\text { matriz curricular } \\
\text { disponível na } \\
\text { página do curso }\end{array}$ & $\begin{array}{c}\text { Instituições com } \\
\text { disciplinas de } \\
\text { neurociência na } \\
\text { matriz curricular }\end{array}$ \\
\hline Paraná & 15 & 2 & 0 \\
\hline
\end{tabular}




\begin{tabular}{|l|c|c|c|}
\hline Santa Catarina & 9 & 3 & 0 \\
\hline Rio Grande do Sul & 16 & 2 & 0 \\
\hline
\end{tabular}

Conforme observado no Quadro 1, observa-se que 7 cursos de um total de 40 não puderam ser averiguados, pois estes não disponibilizavam as matrizes curriculares vigentes na página eletrônica do curso.

Portanto, os resultados geram conclusões que podem ser generalizadas apenas para $82,5 \%$ do público-alvo da pesquisa. Dessa porcentagem, então, verificou-se que nenhum dos cursos oferta disciplinas obrigatórias de neurociência durante a formação do professor de Física.

Tais resultados vão ao encontro dos achados das pesquisas supracitadas realizadas em outras áreas do conhecimento (GROSSI, et. al., 2014), e (FONSECA; CÁSSIA, 2012). Nesses trabalhos notou-se também pouca adesão à integração entre licenciatura e neurociência, sendo pontual os cursos nos quais apresentavam disciplinas da área ou de áreas correlatas com a temática em nível nacional.

Sobre os resultados deste artigo, é importante salientar que foi possível perceber que todas as matrizes curriculares analisadas possuem disciplinas que discorrem sobre tópicos de aprendizagem, porém centrando esta abordagem dentro da psicologia cognitiva, apenas.

\section{DISCUSSÕES}

Com base nos resultados observados, pode-se notar que ainda há uma lacuna a suprir quando o assunto é aproximar os conhecimentos da neurociência aos da educação, em especial, ao Ensino de Física. Conforme discutido, esta proximidade deve acontecer com cautela, para que haja um crescimento de ambas as áreas do conhecimento e não somente uma apropriação imediatista e paliativa de conceitos neurobiológicos a atividades de ensino (GUERRA, 2011). Defende-se essa interlocução, pois de uma perspectiva interdisciplinar, acredita-se que os desafios do ensino possam ser superados com maior êxito.

A motivação que sustentou a realização desta pesquisa, deu-se ao compreender que para essas áreas obterem sucesso nessa relação interdisciplinar, é necessário que os esforços de aproximação aconteçam desde a formação do professor. 
Sendo assim, julga-se importante que disciplinas regulares forneçam um primeiro contato do licenciando com a possibilidade de compreender aspectos da aprendizagem do ponto de vista do conhecimento atual que se tem sobre o tema.

Embora se defenda a relevância da relação entre neurociência e educação, é importante compreender que há diferença entre apenas obter o conhecimento dos mecanismos cerebrais e realizar uma aplicação significativa na área da educação, pois estas são duas áreas com formatos epistemológicos, metodológicos e experienciais distintos. Isso sinaliza que não basta somente fazer uso de princípios de uma área em outra, sem considerar todo o contexto do sistema educacional e a realidade de uma sala de aula.

Segundo Rato e Caldas (2010) a aproximação desses dois campos auxilia no combate a interpretações precipitadas e aplicações não efetivas entre as duas perspectivas. Os autores afirmam que este distanciamento também é observado na realidade de Portugal, corroborando com a ideia defendida neste trabalho de que atualmente se torna imprescindível o diálogo entre as duas áreas, salientando a necessidade de mais produções que sensibilizem para a importância de pesquisadores de ambas as ciências se dedicarem à esta temática interdisciplinar.

Seria importante para o professor concluir sua formação inicial compreendendo tais conhecimentos, mas sobretudo, com uma visão prática de como tais elementos podem o auxiliar nas suas estratégias cotidianas de ensino. Tais cautelas, remetem à defesa de uma investigação rigorosa e científica dos achados da neurociência aplicados à sala de aula, conforme defende Guerra (2011):

\footnotetext{
A falta de conhecimento dos neurocientistas sobre o processo ensinoaprendizagem na sala de aula e sobre metodologia e teoria educacionais básicas é mais um fator a ser contornado. A psicologia educacional, desempenhada por educadores capacitados em neurociências básicas, poderá contribuir para o uso adequado dos achados das neurociências e para a colaboração entre as duas áreas. A inclusão dos fundamentos neurobiológicos do processo ensino-aprendizagem na formação inicial do educador proporcionará nova e diferente perspectiva da educação e de suas estratégias pedagógicas, influenciando também a compreensão dos aspectos sociais, psicológicos, culturais e antropológicos tradicionalmente estudados pelos pedagogos (p. 4).
} 
Para o autor, a neurociência não atua como uma solução para os desafios da educação, nem traz uma receita pronta de como ensinar, porém, ela se constitui como uma ferramenta que contribui para as práticas da sala de aula.

\begin{abstract}
Descobertas em neurociências não se aplicam direta e imediatamente na escola. A aplicação desse conhecimento no contexto educacional tem limitações. As neurociências podem informar a educação, mas não a explicar ou fornecer prescrições, receitas que garantam resultados. Teorias psicológicas baseadas nos mecanismos cerebrais envolvidos na aprendizagem podem inspirar objetivos e estratégias educacionais. $\mathrm{O}$ trabalho do educador pode ser mais significativo e eficiente se ele conhece o funcionamento cerebral, o que lhe possibilita desenvolvimento de estratégias pedagógicas mais adequadas (GUERRA, 2011, p.3).
\end{abstract}

Sugere-se criar articulações entre os teóricos da educação, como Piaget, Wallon, Vygotsky, Ausubel, entre outros, pois estes sempre refletiram sobre a aprendizagem. Porém, a neurociência contribui com a educação ao passo que elucida o funcionamento fisiológico deste processo, proporcionando aprofundamento das conclusões sobre esse movimento e, por conseguinte, respaldando formas de ensino que podem ser efetivamente de maior significado, quando comparados com o modelo considerado comumente como tradicional.

Para as matrizes curriculares analisadas, percebeu-se que há potencialidade de que tais tópicos sejam abordados na licenciatura, em um primeiro momento, por meio de disciplinas eletivas ou até mesmo como sugestão de inclusão em discussões das disciplinas destinadas à psicologia da aprendizagem, pois em todos os documentos analisados, encontrou-se cadeiras destinadas a esse tema, com tópicos nos quais a neurociência poderia ser objeto de estudo.

Não obstante, dada a relevância da discussão para a formação dos professores, é notável a importância de que disciplinas com o foco em aspectos da neurociência estejam presentes na grade obrigatória dos cursos de licenciatura em Física e demais áreas.

Para um professor, assim como são importantes os conhecimentos teóricos e os saberes docentes de sua área, são relevantes também conhecimentos que o possibilite atuar de maneira crítica e responsável em situações do cotidiano escolar. Aspectos relativos à aprendizagem de seus alunos, assim como as dificuldades de tal objetivo, necessitam de um saber multidimensional para compreender suas causas e planejar 
ações que recuperem esse déficit e potencializem uma aprendizagem significativa aos estudantes.

Nesse sentido, entende-se que a neurociência, por si só, não é a panaceia que poderá resolver os problemas do sistema educacional, mas pode ser uma ferramenta de auxílio aos docentes, fornecendo bases para compreender, de maneira abrangente, as idiossincrasias da aprendizagem humana.

A sala de aula, por sua vez, tanto no ambiente universitário, quanto na educação básica, é um lugar privilegiado para que a pesquisa e experimentação da neurociência possam testar suas proposições de maneira prática, pois o processo de aprendizagem escolar envolve não somente fatores passiveis de serem controlados em um laboratório, pois abrangem também aspectos socioculturais, psicoemocionais e também, neurológicos.

Nesse sentido, saber como o estudante aprende e como se pode potencializar tal processo para aprender melhor é uma pergunta com possibilidades de respostas que poderiam trazer contribuições significativas para o sistema educacional. Questionamentos como: há momentos nos quais existe maior propensão ao aprendizado? qual a influência das emoções na consolidação da aprendizagem? o que é inteligência, ela pode ser genética? o quanto o sono influencia no aprendizado? entre outros, podem compor o escopo de muitas pesquisas e discussões dentro do cenário educacional, repensando os currículos, as avaliações, as relações de causa e efeito entre ensino e aprendizagem, entre outros tópicos.

Porém, uma vez que a importância dessa perspectiva é um fato corroborado pela tendência educacional atual, se faz importante questionar: porque se nota a ausência destes conhecimentos nos currículos de licenciatura em Física e quais os motivos que impossibilitam sua discussão efetiva dentro da formação inicial do professor?

Esses questionamentos podem se transformar em problemáticas sugeridas para o aprofundamento desse estudo em publicações subsequentes, uma vez que o caráter da pesquisa aqui relatada teve uma visão preliminar e exploratória da realidade escolhida, não se destinando à apontar práticas de mudança nas graduações em Física do sul do Brasil, pois tal meta exige maior aprofundamento da temática e da realidade universitária observada. 


\section{CONSIDERAÇÕES}

Uma pesquisa documental foi realizada em 40 cursos de licenciatura em Física do sul do Brasil, com o objetivo de observar se há disciplinas regulares que discutam aspectos de neurociência dentro da formação do professor de Física. Os resultados recuperados demonstraram que até o momento da escrita deste artigo, nenhum curso oferece esta ocasião.

Dessa forma, considera-se que a neurociência não está presente em disciplinas obrigatórias da formação do professor de Física na região Sul do Brasil de maneira direta. Como perspectiva para futuros estudos, sugere-se que as demais regiões do país sejam englobadas em análise semelhante, a fim de traçar um panorama nacional da realidade estudada. Sugere-se também que sejam realizadas análises em demais cursos de licenciatura, como licenciaturas em Biologia, Química, Ciências Naturais, e de outras áreas do conhecimento.

O fato de não ter sido encontrada nenhuma disciplina sobre neurociência demonstra que ainda há muita discussão a se concretizar para explanar aos pesquisadores e formadores de professores da área, a importância deste trabalho interdisciplinar.

Embora não deva ser considerada como a solução para os desafios do Ensino de Física, o conhecimento do funcionamento orgânico do cérebro, aliado às teorias cognitivas, pode servir de subsídio teórico para analisar quais práticas pedagógicas podem proporcionar maior efeito no processo de ensino e aprendizagem de conteúdos de Física.

Acredita-se também, que conhecer o funcionamento do cérebro do aluno, auxilia o professor a compreender de forma mais ampla a sua individualidade. Isto significa estar atento, por exemplo, a como funciona a memória, motivação, retenção de conhecimentos, formas de aprendizagem, entre outros fatores, e assim, buscar modos de intervir com maior abrangência na discussão dos fenômenos a serem abordados, bem como modos de estimular com maior efetividade este indivíduo, para que este possua meios de alcançar sua potencialidade de aprender.

\section{REFERÊNCIAS}


ANDRADE, P.E; PRADO, P. S. T. Psicologia e Neurociência cognitivas: Alguns avanços recentes e implicações para a educação. Interação em Psicologia, Curitiba, volume 07, n. 2, p. 73-80, 2003.

AUSUBEL, D.P. Aquisição e retenção de conhecimentos: uma perspectiva cognitiva. Lisboa: Plátano, v. 1, 2003.

BARTOSZECK, A.B. Neurociência na educação. Revista Eletrônica Faculdades Integradas Espírita, Curitiba, volume 01, p. 1-6, 2006.

BARTOSZECK, A.B; BARTOSZECK, Flavio Kulevicz. Percepção do professor sobre neurociência aplicada à educação. Educere - Revista da Educação da UNIPAR, Umuarama, volume 09, n. 1, p. 7-32, 2009.

BROCKINGTON, G. Neurociência e Educação: investigando o papel da emoção na aquisição e uso do conhecimento científico. 2011. 202p. Tese (Doutorado em Educação). Faculdade de Educação. Universidade de São Paulo, São Paulo.

FERNANDES, R. S.; PARK, M.B. Lembrar-esquecer: trabalhando com as memórias infantis. Cadernos Cedes. Campinas, volume 26, n. 68, p. 39-59, 2006.

FONSECA, L; CÁSSIA, A. Um estudo preliminar sobre a neurociência cognitiva nos cursos de licenciatura em matemática de Sergipe/Brasil: necessidades de incorporação de uma Engenharia neurodidática. Colóquio Internacional Educação e Contemporaneidade, volume 6, 2012.

GIL, A.C. Como elaborar projetos de pesquisa. $4^{\text {a }}$ edição. São Paulo: Atlas, 2007

GUERRA, L. B. O diálogo entre a neurociência e a educação: da euforia aos desafios e possibilidades. Revista Interlocução, Belo Horizonte, volume 04, n. 4, p. 3-12, 2011.

GROSSI, M. G. R; LOPES, A. M; COUTO, P.A. A neurociência na formação de professores: um estudo da realidade brasileira. Revista da FAEEBA-Educação e Contemporaneidade, Salvador, volume 23, n. 41, p. 27-40, 2014.

IZQUIERDO, I. Questões sobre memória. 1 ${ }^{a}$ Edição. São Leopoldo: Editora Unisinos, 2006. Lent, 2010.

A arte de esquecer: cérebro e memória. $2^{\text {a }}$ Edição. Rio de Janeiro: Vieira e

LENT, R. Cem bilhões de neurônios: conceitos fundamentais de neurociência. $2^{\text {a }}$ Edição. Rio de Janeiro: Atheneu, 2004.

OLIVEIRA, G, G. Neurociências e os processos educativos: um saber necessário na formação de professores. Educação Unisinos, São Leopoldo, volume 18, n. 1, p. 13-24, 2014. 
RATO, J.R; CALDAS, A. C. Neurociências e educação: Realidade ou ficção? In C. Nogueira, I. Silva, L. Lima, A. T. Almeida, R. Cabecinhas, R. Gomes, C. Machado, A. Maia, A. Sampaio, e M. C. Taveira (Eds.), Atas do Simpósio Nacional de Investigação em Psicologia (p. 626-644). Disponível em: $<$ http://www.actassnip2010>; Acesso em: $\mathrm{abril} / 2018$.

RELVAS, M.P. Neurociência e educação. $1^{\text {a }}$ Edição. Rio de Janeiro: Wak Editora, 2009.

Neurociência e transtornos de aprendizagem: as múltiplas eficiências para

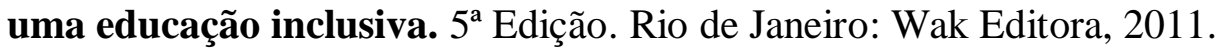

